\title{
High-rate deposition of nano- crystalline silicon thin films on plastics
}

\author{
E. Marins ${ }^{*}$, , V. Guduru ${ }^{1}$, M. Ribeiro ${ }^{2}$, F. Cerqueira ${ }^{1}$, A. Bouattour ${ }^{3}$ and P. Alpuim ${ }^{1}$ \\ ${ }^{1}$ Centro de Física, Universidade do Minho, 4800-058 Guimarães, 4710-057 Braga, Portugal \\ ${ }^{2}$ Centro de Nanotecnologia e Materiais Técnicos, Funcionais e Inteligentes (CeNTI), 4760-034 Vila Nova de Famalicão, Portugal \\ ${ }^{3}$ Institut für Physikalische Elektronik (ipe), Universität Stuttgart, 70569 Stuttgart, Germany
}

Received ZZZ, revised ZZZ, accepted ZZZ

Published online ZZZ (Dates will be provided by the publisher.)

Keywords Nanocrystalline silicon, thin films, high-rate deposition, solar cells

* Corresponding author: e-mail emarins@fisica.uminho.pt, Phone: +351 253510 466, Fax: +351 253510461

Nanocrystalline silicon (nc-Si:H) is commonly used in the bottom cell of tandem solar cells. With an indirect bandgap, nc$\mathrm{Si}: \mathrm{H}$ requires thicker $(\sim 1 \mu \mathrm{m})$ films for efficient light harvesting than amorphous $\mathrm{Si}(\mathrm{a}-\mathrm{Si}: \mathrm{H})$ does. Therefore, thin-film high deposition rates are crucial for further cost reduction of highly efficient a-Si:H based photovoltaic technology. Plastic substrates allow for further cost reduction by enabling roll-to-roll inline deposition.

In this work, high nc-Si:H deposition rates on plastic were achieved at low substrate temperature $\left(150^{\circ} \mathrm{C}\right)$ by standard $\mathrm{Ra}-$ dio-frequency (13.56 MHz) Plasma Enhanced Chemical Vapor Deposition. Focus was on the influence of deposition pressure, inter-electrode distance $(1.2 \mathrm{~cm})$ and high power coupled to the

1 Introduction Hydrogenated amorphous silicon (a$\mathrm{Si}: \mathrm{H})$ has been widely used in the manufacture of low cost solar cells and panels. The addition of a nanocrystalline silicon (nc-Si:H) bottom cell in high efficiency multi-junction solar cells [1-2] improves conversion efficiency and solar cell stability under illumination. It also brings about the need to increase the absorption layer deposition rate, since a much thicker nc-Si:H layer is required to absorb the same amount of light as a-Si:H does. Moreover, nc-Si:H films are normally deposited under conditions of very high hydrogen dilution of silane, which dramatically lowers the deposition rate under standard radio-frequency (13.56 $\mathrm{MHz}$ ) Plasma Enhanced Chemical Vapor Deposition (rfPECVD) conditions. Therefore, increasing the deposition rate, while keeping up the film electronic quality, is an essential step to enable industrial production at a competitive price of next generation thin-film Si solar cells. High deposition rates have been demonstrated using VHF-PECVD [3]. However, in large-area deposition systems, conventional rf-PECVD is preferred because it facilitates homogeneous deposition over large areas [4] and because it is familiar to the industry. Several groups reported in the literature the key role of using a high pressure deposition regime to achieve high quality solar cells at high deposition rates by rf-PECVD [5-6]. Using a small inter-electrode distance can also slightly increase the deposition rate [7] but, plasma, on the hydrogen-to-silane dilution ratios (HD) necessary to achieve the amorphous-to-nanocrystalline phase transition and on the resulting film deposition rate. For each pressure and rfpower, there is a value of HD for which the films start to exhibit a certain amount of crystalline fraction. For constant rf-power, this value increases with pressure. Within the parameter range studied the deposition rate was highest $(0.38 \mathrm{~nm} / \mathrm{s})$ for $\mathrm{nc}-\mathrm{Si}: \mathrm{H}$ films deposited at 6 Torr, $700 \mathrm{~mW} / \mathrm{cm}^{2}$ using HD of $98.5 \%$. Decreasing the pressure to 3 Torr (1.5 Torr) and rf-power to 350 $\mathrm{mW} / \mathrm{cm}^{2}$ using HD $=98.5 \%$ deposition rate is $0.12 \mathrm{~nm} / \mathrm{s}(0.076$ $\mathrm{nm} / \mathrm{s})$. Raman crystalline fraction of these films is 72,62 and $53 \%$ for the 6,3 and 1.5 Torr films, respectively.

more important for industrial reactors, it avoids the use of large gas volumes and saves pumping power.

Thin-film photovoltaics can only compete in a market dominated by highly efficient c-Si technology if they offer very low price and/or focus on niche markets. One way to achieve both goals is to use flexible, inexpensive plastic substrates which moreover lend themselves to inline high throughput fabrication processes.

This paper describes the optimization of a-Si:H and nc$\mathrm{Si}: \mathrm{H}$ intrinsic and doped layers deposited by rf-PECVD on plastic $(\mathrm{PEN})$ at $150^{\circ} \mathrm{C}$. A small $(1.2 \mathrm{~cm})$ inter-electrode distance was used. Focus was placed in the influence of deposition pressure and power coupled to the plasma, on the deposition rate and film electronic quality.

2 Experimental a-Si:H and nc-Si:H thin films were deposited by rf-PECVD on $125 \mu \mathrm{m}$ thick plastic substrates (PEN, polyethylene terephthalate) using $\mathrm{SiH}_{4}$ diluted in $\mathrm{H}_{2}$. HD between 96 and $99 \%$ was used [HD $=F_{\mathrm{H} 2} /\left(F_{\mathrm{SiH} 4}+\right.$ $\left.F_{\mathrm{H} 2}\right) \times 100 \%$, where $F$ 's are gas flow rates. Substrates were clamped to the top earthed electrode, placed $1.2 \mathrm{~cm}$ from the bottom powered electrode, in a parallel plate capacitor configuration, and heated to the deposition temperature $T_{\text {sub }}=150^{\circ} \mathrm{C}$. Three HD-series of films were prepared at deposition pressure $p_{\mathrm{w}}=1.5,3$ and 6 Torr. In all series rfpower, $P_{\mathrm{rf}}$, was $10 \mathrm{~W}$, corresponding to a power density of $350 \mathrm{~mW} / \mathrm{cm}^{2}$. The 6 Torr series was repeated using $P_{\mathrm{rf}}=$ $20 \mathrm{~W}$ (power density $=700 \mathrm{~mW} / \mathrm{cm}^{2}$ ). 
Deposition rate, $r_{\mathrm{d}}$, was derived from the thickness obtained by analysis of interference fringes in the UVvisible-NIR transmittance spectra and confirmed by profilometry. Film structure was studied by Raman and FTIR spectroscopy. The Raman crystalline fraction, $X_{\mathrm{c}}$, and crystallite size, $d_{\mathrm{nc}}$, of the films was calculated according to reference [8]. For the amorphous films, the bond angle deviation $\Delta \theta$ was related to the full width at half maximum (FWHM) $\Gamma$ of the TO peak centered at $480 \mathrm{~cm}^{-1}$. Room temperature dark conductivity, $\sigma_{\mathrm{dk}}$, and secondary photoconductivity, $\sigma_{\mathrm{ph}}$, were measured between coplanar Al contacts $6 \mathrm{~mm}$ long with $1 \mathrm{~mm}$ gap. Urbach tails and deep defect absorption were obtained from Constant Photocurrent Measurements (CPM).
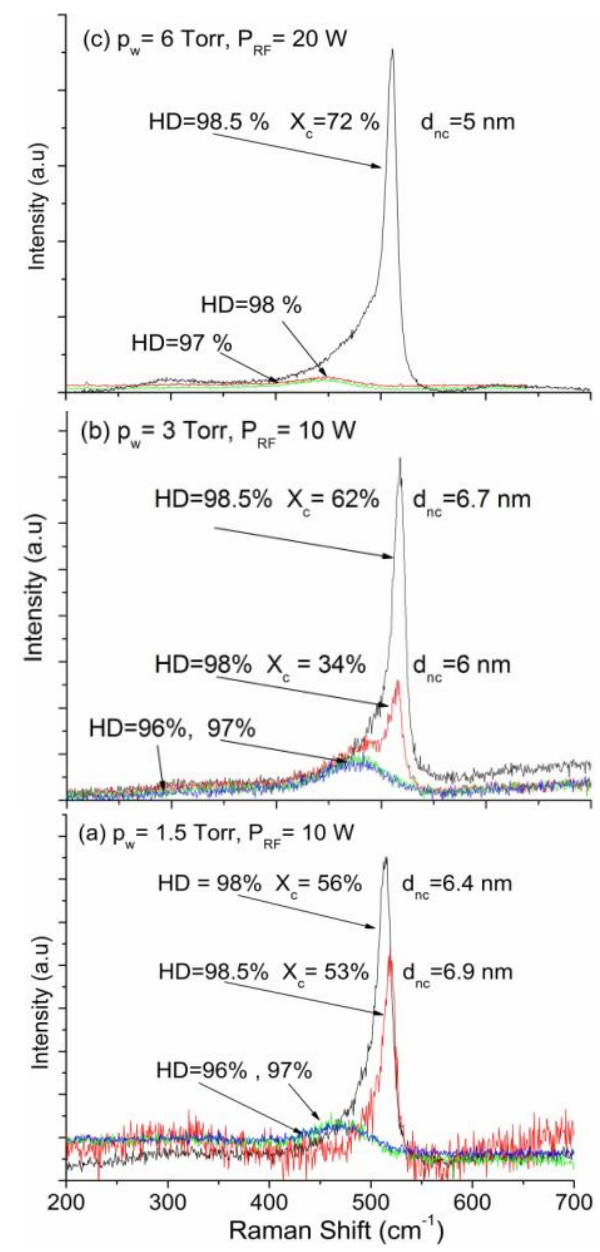

Figure 1 Raman spectra for samples deposited on PEN at (a) $p_{w}=$ 1.5 Torr and $P_{r f}=10 \mathrm{~W}$, (b) $p_{w}=3$ Torr and $P_{r f}=10 \mathrm{~W}$ and (c) $p_{w}=$ 6 Torr and $P_{r f}=20 \mathrm{~W}$, using different hydrogen dilutions near the amorphous to nanocrystalline transition point. $\mathrm{X}_{\mathrm{c}}$ is crystalline fraction and $d_{\mathrm{nc}}$ is crystallite size.

\section{Results and discussion}

3.1 Structural properties Raman spectra of films deposited under $\mathrm{HD}=97,98$ and $98.5 \%$ at $p_{\mathrm{w}}=1.5$ Torr [fig. 1(a)], 3 Torr [fig. 1(b)] and 6 Torr [fig. 1(c)] show that for $\mathrm{HD}=98 \%$ their structure is amorphous at 6 Torr and nanocrystalline at 3 and 1.5 Torr $\left(X_{\mathrm{c}}=34 \%\right.$ and $56 \%$, respectively). It is concluded that the hydrogen induced amorphous-to-nanocrystalline transition $(\mathrm{a} \rightarrow \mathrm{nc})$ requires a progressively higher HD as the pressure is increased from 1.5 to 3 and 6 Torr. At 6 Torr the $\mathrm{a} \rightarrow \mathrm{nc}$ transition occurs only for $\mathrm{HD}=98.5 \%$ after increasing rf-power to $20 \mathrm{~W}$ [fig.1(c)]. Films deposited at 6 Torr and $P_{\mathrm{rf}}=10 \mathrm{~W}$ (not shown) are amorphous up to extreme $\mathrm{HD}=99 \%$ at which the $\mathrm{a} \rightarrow \mathrm{nc}$ occurs $\left(X_{\mathrm{c}} \sim 70 \%\right)$. This finding can be correlated with results in literature that show, in high $\mathrm{H}_{2}$ diluted silane plasmas, a progressive shift in concentration of positive ion species from $\mathrm{H}^{+}$to $\mathrm{SiH}_{\mathrm{m}}{ }^{+}$as pressure increases in the range 0.1-10 Torr. Moreover, the concentration of positive ions becomes much higher than that of neutral radicals as $p_{\mathrm{w}} \rightarrow 10$ Torr [9].

For all pressures and rf-powers studied the a $\rightarrow$ nc occurs abruptly, within a $0.5-1 \%$ interval in the HD scale. Nanocrystalline samples deposited at 6 Torr have lower sized $(<5 \mathrm{~nm})$ Si nanocrystals, when compared to the films deposited at 1.5 and 3 Torr (crystallite size $\sim 7 \mathrm{~nm}$ ). This effect is clearly seen in the Raman spectra by the shift of the crystalline peak towards the low wave number side.

3.2 Deposition rate Increasing the deposition rate of nc:Si-H films is an objective central to the present work Figure 2 shows the deposition rate, $r_{\mathrm{d}}$, as a function of HD for films deposited at $1.5\left(P_{\mathrm{rf}}=10 \mathrm{~W}\right), 3\left(P_{\mathrm{rf}}=10 \mathrm{~W}\right)$ and 6 Torr $\left(P_{\mathrm{rf}}=10\right.$ and $\left.20 \mathrm{~W}\right)$ (see also Table $\mathrm{I}$ in last section). Also shown, for comparison, are HD series of films deposited at a larger inter electrode distance $(4 \mathrm{~cm})$ using high pressure (1.5 Torr) and high power $(10 \mathrm{~W})$ and using low pressure $(160 \mathrm{mTorr})$ and low power $(2 \mathrm{~W} \Leftrightarrow 60$ $\left.\mathrm{mW} / \mathrm{cm}^{2}\right)$. In general, $r_{\mathrm{d}}$ increases with pressure and $\mathrm{rf}-$ power, and decreases with inter electrode distance. For example $r_{\mathrm{d}}$ increases from 0.04 to $0.1 \mathrm{~nm} / \mathrm{s}$ at $\mathrm{HD}=$ $98.5 \%, P_{\mathrm{rf}}=10 \mathrm{~W}$ and $p_{\mathrm{w}}=1.5 \mathrm{Torr}$, when the inter electrode gap decreases from 4 to $1.2 \mathrm{~cm}$.

It is known that during the deposition process silylene $\left(\mathrm{SiH}_{2}\right)$ and silyl $\left(\mathrm{SiH}_{3}\right)$ radicals generated by the chemical reactions between the secondary species in the plasma, mainly determine the film growth rate. Even though silyl radicals will diffuse towards the film surface at both electrode distances, they have however less relative incorporation probability $(0.1)$ into the film for the shorter distance[10]. This is because the survival rate of the much more reactive $\mathrm{SiH}_{2}$ radicals, having the diffusion length around $0.5 \mathrm{~cm}$ and high incorporation probability $(0.65-$ $0.8)[11]$ into the film, is favoured by the short distance between the electrodes. Possibly the silylene radicals are therefore playing an important role in increasing the deposition rate when the inter electrode gap is reduced.

In fig.2, data points with abscissa $\mathrm{HD}=98.5 \%$ corres- 


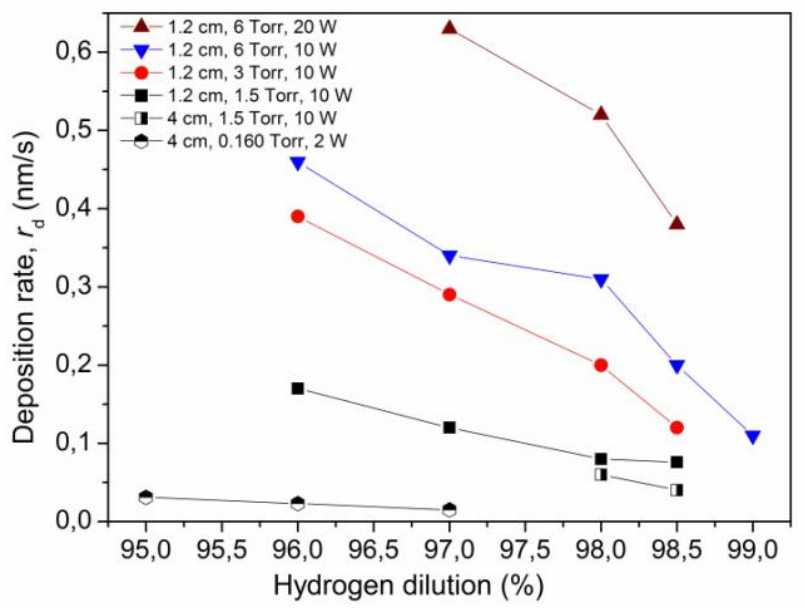

Figure 2 Deposition rate as a function of HD for films deposited on plastic substrates at different pressures $(0.160,1.5,3$, and 6Torr) and rf-power (2, 10 and $20 \mathrm{~W})$.

pond, with one exception at 6 Torr $(10 \mathrm{~W})$, to nanocrystalline films with $X_{\mathrm{c}}>50 \%$. $r_{\mathrm{d}}$ increases $\sim 10$-fold from bottom to top, i.e. from $0.04 \mathrm{~nm} / \mathrm{s}$ at 1.5 Torr $(10 \mathrm{~W})$ to 0.38 $\mathrm{nm} / \mathrm{s}$ at 6 Torr $(20 \mathrm{~W})$. The transition from an amorphous film at $p_{\mathrm{w}}=6$ Torr $(10 \mathrm{~W})$ to a highly crystalline one $\left(X_{\mathrm{c}}=\right.$ $72 \%)$ at $p_{\mathrm{w}}=6$ Torr $(20 \mathrm{~W})$ might correspond to the threshold of a high-pressure $\mathrm{SiH}_{4}$ depletion regime, thus inhibiting the $\mathrm{H}$ annihilation reaction $\left(\mathrm{H}+\mathrm{SiH}_{4} \rightarrow \mathrm{H}_{2}+\mathrm{SiH}_{3}\right)$ and consequently increasing atomic $\mathrm{H}$ concentration. It was found in ref.[12] that this high rate deposition regime for $\mathrm{nc}-\mathrm{Si}: \mathrm{H}$ preserves the high electronic quality of the films.

3.3 Opto-electronic properties Table I summarizes important optical and electronic properties of selected samples. Figure 3 shows the photo-to-dark conductivity ratio (photosensitivity, $S$ ) as a function of HD. Two groups of films can be identified: those obtained at lower $\mathrm{H}_{2}$ dilution, with high photosensitivity, and those obtained at higher values of HD, with lower photosensitivity. The maximum value of photosensitivity $\left(S=4 \times 10^{6}\right)$ is obtained for the film deposited at 1.5 Torr, $\mathrm{HD}=96 \%$ and $P_{\mathrm{rf}}=10$ W. Photosensitivity remains high $\left(\sim 10^{6}\right)$ for HD up to $98.5 \%$ at 6 Torr $(10 \mathrm{~W})$. For deposition pressures of 1.5 and 3 Torr or 6 Torr $(20 \mathrm{~W}) S$ drops abruptly at $\mathrm{HD}=98$ and $98.5 \%$, respectively. If one combines the information conveyed in fig. 3 with the results of the Raman analysis in section 3.1 one concludes that amorphous films are those that exhibit high $S$-values while a nanocrystalline film structure is typical of the low photosensitivity samples, due to their indirect bandgap that strongly reduces the optical absorption. The photosensitivity of films deposited at 6 Torr reaches its maximum value right before the $\mathrm{a} \rightarrow \mathrm{nc}$ transition. The amorphous films with high photosensitivity $\left(>10^{5}\right)$ are good candidates for the fabrication of the top solar cell in tandem or triple junction structures.

Results from CPM measurements made in the a-Si:H films show Urbach tails increasing with deposition pres- sure from $64 \mathrm{meV}$ at 1.5 Torr to $81 \mathrm{meV}$ at 3 Torr and 85 $\mathrm{meV}$ at 6 Torr. These values, particularly for the higher $p_{\mathrm{w}^{-}}$ films, are rather high and one may speculate that they are a consequence of incorporation of dust from the plasma during deposition. Otherwise it is hard to understand how such broad band tails can coexist with the film high photosensitivity shown. Dangling bond concentration, obtained from the CPM spectra, is $\sim 3.5 \times 10^{17} \mathrm{~cm}^{-3}$ in these films. Bond angle disorder, $\Delta \theta$, is $6.79,6.94$ and 6.96 for the films deposited at 1.5, 3 and 6 Torr, respectively.

3.4 Doping Phosphine $\left(\mathrm{PH}_{3}\right)$ or diborane $\left(\mathrm{B}_{2} \mathrm{H}_{6}\right)$ were added to the reactive gas mixture, while keeping up the deposition conditions that yielded the best nc-Si:H (higher $X_{\mathrm{C}}$ ) and a-Si:H films (higher $S$ ) to obtain n- or p-type films, respectively. Results can be seen in Fig. 4 where $\sigma_{\mathrm{dk}}$ is plotted as a function of the its activation energy, $E_{\mathrm{a}, \mathrm{dk}}$, for films deposited at $p_{\mathrm{w}}=1.5,3$ and 6 Torr. For n-type films $R$, defined as the dopant-gas to silane flow rate ratio, was kept constant and equal to 2.5. For p-type films $R$ was varied in the interval $[0.5,2.5](R=0.5,1,1.5,2$ and 2.5$)$.

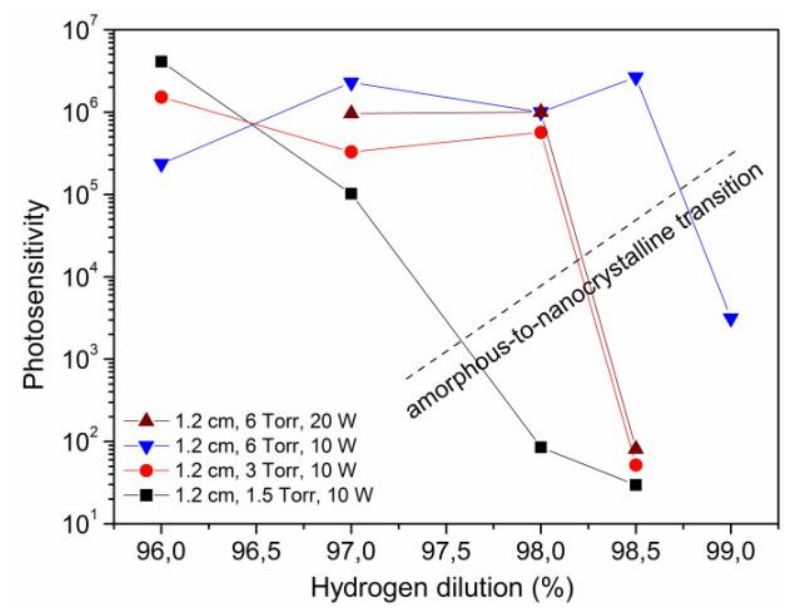

Figure 3 Photosensitivity as a function of HD for films deposited on plastic substrates at different pressures $(1.5,3$, and 6Torr) and rf-power (10W and 20W).

N-type nc-Si:H films with $\sigma_{\mathrm{dk}}=0.69 \Omega^{-1} \mathrm{~cm}^{-1}\left(E_{\mathrm{a}, \mathrm{dk}}=49\right.$ $\mathrm{meV})$ and $7.8 \Omega^{-1} \mathrm{~cm}^{-1}\left(E_{\mathrm{a}, \mathrm{dk}}=24 \mathrm{meV}\right)$ were obtained at 1.5 and 3 Torr, respectively. At 6 Torr it was not possible to obtain highly P-doped films because their structure was strongly amorphized by the dopants. Consequently the highest $\sigma_{\mathrm{dk}}$ was only $2 \times 10^{-2} \Omega^{-1} \mathrm{~cm}^{-1}\left(E_{\mathrm{a}, \mathrm{dk}}=140 \mathrm{meV}\right)$. The most strongly P-doped a-Si:H film was obtained at 3 Torr, followed by the film deposited at 1.5 Torr. In both cases $\sigma_{\mathrm{dk}} \sim 10^{-3} \Omega^{-1} \mathrm{~cm}^{-1}\left(E_{\mathrm{a}, \mathrm{dk}} \sim 0.25 \mathrm{eV}\right)$.

P-type nc-Si:H films with $\sigma_{\mathrm{dk}} \sim 1 \Omega^{-1} \mathrm{~cm}^{-1}\left(E_{\mathrm{a}, \mathrm{dk}} \sim 30\right.$ meV) were obtained at 1.5 and 3 Torr, using $R=1$ and 0.5 , respectively. At 6 Torr it was not possible to obtain Bdoped nanocrystalline films. The highest p-type conductivity obtained for a-Si:H films was $\sim 5 \times 10^{-7} \Omega^{-1} \mathrm{~cm}^{-1}$ $\left(E_{\mathrm{a}, \mathrm{dk}} \sim 0.5 \mathrm{eV}\right)$ for $R=2.5$, obtained at all pressures studied. 
Table I Deposition conditions, structural and optoelectronic properties of selected intrinsic films on PEN.

\begin{tabular}{cccccccccc}
\hline Sample & $\begin{array}{c}p_{w} \\
(\text { Torr })\end{array}$ & $\begin{array}{c}P_{\mathrm{rf}} \\
(\mathrm{W})\end{array}$ & $\begin{array}{c}\mathrm{HD} \\
(\%)\end{array}$ & $\begin{array}{c}r_{\mathrm{d}} \\
(\AA / \mathrm{s})\end{array}$ & $\begin{array}{c}E_{\mathrm{opt}} \\
(\mathrm{eV})\end{array}$ & $\begin{array}{c}\sigma_{\mathrm{dk}} \\
\left(\Omega^{-1} \mathrm{~cm}^{-1}\right)\end{array}$ & $\begin{array}{c}\sigma_{\mathrm{ph}} \\
\left(\Omega^{-1} \mathrm{~cm}^{-1}\right)\end{array}$ & $\begin{array}{c}E_{\mathrm{a}, \mathrm{dk}} \\
(\mathrm{eV})\end{array}$ & $\begin{array}{c}X_{\mathrm{C}} \\
(\%)\end{array}$ \\
\hline S844 & 1.5 & 10 & 96 & 0.17 & 1.5 & $5.1 \times 10^{-11}$ & $2.1 \times 10^{-4}$ & 0.62 & 0 \\
$\mathrm{~S} 847$ & 3 & 10 & 98 & 0.2 & 1.75 & $4.2 \times 10^{-10}$ & $2.4 \times 10^{-4}$ & 0.64 & 34 \\
$\mathrm{~S} 857$ & 6 & 10 & 98 & 0.31 & 1.85 & $4.8 \times 10^{-10}$ & $4.8 \times 10^{-4}$ & 0.57 & 0 \\
$\mathrm{~S} 887$ & 6 & 20 & 98 & 0.52 & 1.6 & $1.2 \times 10^{-11}$ & $1.2 \times 10^{-5}$ & 0.74 & 0 \\
$\mathrm{~S} 843$ & 1.5 & 10 & 98.5 & 0.07 & 2.1 & $3.4 \times 10^{-6}$ & $1.0 \times 10^{-4}$ & 0.38 & 53 \\
$\mathrm{~S} 846$ & 3 & 10 & 98.5 & 0.12 & 2.0 & $4.8 \times 10^{-6}$ & $2.5 \times 10^{-4}$ & 0.42 & 62 \\
$\mathrm{~S} 873$ & 6 & 10 & 99 & 0.10 & 2.0 & $1.2 \times 10^{-8}$ & $3.9 \times 10^{-5}$ & 0.55 & 74 \\
$\mathrm{~S} 874$ & 6 & 20 & 98.5 & 0.38 & 1.5 & $3.1 \times 10^{-7}$ & $2.5 \times 10^{-5}$ & 0.47 & 72 \\
\hline
\end{tabular}

phase film was obtained at 6 Torr, $20 \mathrm{~W}$ and had photosen-

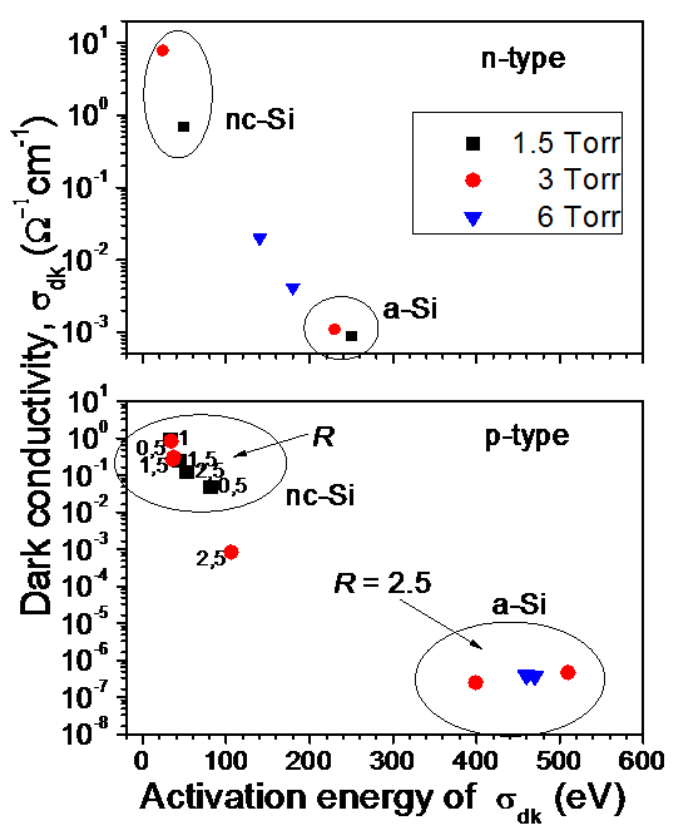

Figure 4 Dark conductivity as a function of activation energy for p- and n-doped films deposited on PEN at different pressures (1.5, 3 , and 6 Torr) and doping ratios (0.5, 1 and 2.5).

Conclusions The deposition rate of both nc-Si:H and a-Si:H thin films can be increased consistently by: 1) decreasing the inter electrode distance, 2) increasing the deposition pressure, and 3 ) increasing the rf-power. The deposition rate decreases as the HD increases in all deposition conditions. For each pressure and rf-power used, there is a value of hydrogen dilution of silane for which the films undergo an amorphous-to-nanocrystalline phase transition. The exact concentration of $\mathrm{H}_{2}$ required for this transition to occur is a function of the deposition parameters and it increases when the working pressure increases, keeping other parameters constant. At 6 Torr it was necessary to increase simultaneously HD and rf-power in order to obtain nc-Si:H films. The films obtained under such conditions were deposited at the highest nanocrystalline deposition rate $\left(r_{\mathrm{d}}=0.38 \mathrm{~nm} / \mathrm{s}\right)$. The films with high photosensitivity $\left(>10^{5}\right)$ are amorphous. Nanocrystalline films have lower photosensitivity, due to their indirect bandgap. The best nc-Si:H had photosensitivity around $10^{2}$. The best mixed sitivity in excess of $10^{3} . \mathrm{n}$ - and p-type nc-Si:H films were obtained with $\sigma_{\mathrm{dk}}=7.8$ and $0.87 \Omega^{-1} \mathrm{~cm}^{-1}$, respectively. At 6 Torr, it was not possible to obtain highly doped nanocrystalline films. Amorphous films were much highly doped with $\mathrm{P}$ than with $\mathrm{B}$. n-type conductivity was $10^{-3} \Omega^{-1} \mathrm{~cm}^{-1}$ while p-type $\sigma_{\mathrm{dk}}=5 \times 10^{-7} \Omega^{-1} \mathrm{~cm}^{-1}$.

Acknowledgements This work was partially funded by FCT (Fundação para a Ciência e Tecnologia) through pluriannual contract with CFUM and bilateral project DREBM/PICS_CNRS/2010_2012. One of the authors (E. Marins) thanks FCT for the PhD grant SFRH/BD/46740/2008.

\section{References}

[1] V. Shah, J. Meier, E. Vallat-Sauvain, N. Wyrsch, U. Kroll, C. Droz and U. Graf, Sol. Energy Mater. Sol. Cells 78, 469 (2003).

[2] S. Guha and J. Yang, J. Non-Cryst. Solids 352, 1917 (2006).

[3] O. Vetterl, F. Finger, R. Carius, P. Hapke, L. Houben, O. Kluth, A. Lambertz, A. Mück, B. Rech and H. Wagner, Sol. Energy Mater. Sol. Cells 62, 97 (2000).

[4] U. Kroll, D. Fischer, J. Meier, L. Sansonnens, A. Howling and A. Shah, Mater. Res. Soc. Symp. Proc. 557, 121 (1999).

[5] L. Guo, M. Kondo, M. Fukawa, K. Saitoh and A. Matsuda, Jpn. J. Appl. Phys. 37, L1116 (1998).

[6] B. Rech, T. Roschek, T. Repmann, J. Müller, R. Schmitz and W. Appenzeller, Thin Solid Films 427, 157 (2003).

[7] Y. Fukuda, Y. Sakuma, C.H. Fukai, Y. Fujimura, K. Azuma and H. Shirai, Thin Solid Films 386, 256 (2001).

[8] M. Vanacek, J. Kocka, J. Strichlik, Z. Kosicek, O. Stika, and A. Triska, Sol. Energy Mater. 8, 411 (1983).

[9] S. Nunomura and M. Kondo, Appl. Phys. Lett. 93, 231502 (2008).

[10] J. Perrin, M. Shiratani, P. Kae-Nune, H. Videlot, J. Jolly and J. Guillon, J. Vac. Sci. Technol. A 16, 278 (1998).

[11] M. Hertl and J. Jolly, J. Phys. D: Appl. Phys. 33, 381 (2000).

[12] M. Kondo, M. Fukawa, L. Guo and A. Matsuda, J. Non-Cryst. Solids 266, 84 (2000). 